\title{
A population biological approach to the collective dynamics of countries undergoing demographic transition
}

\author{
Utkarsh Dang ${ }^{\mathrm{a}}$, Chris T. Bauch ${ }^{\mathrm{a}, *}$ \\ ${ }^{\text {a }}$ Department of Mathematics and Statistics, University of Guelph, Guelph, Ontario \\ N1G2W1, Canada \\ email: udang@uoguelph.ca (Utkarsh Dang), cbauch@uoguelph.ca (Chris T. Bauch) \\ telephone: 1-519-824-4120 ext. 53079 (Chris T. Bauch) \\ fax: 1-519-837-0221 (Chris T. Bauch) \\ * corresponding author: Chris T. Bauch
}

For submission to the Journal of Theoretical Biology

First submission October 12, 2009

Revised submission February 18, 2010 


\section{Abstract}

Birth rates have been declining in higher-income countries since the middle of the $19^{\text {th }}$ century. A growing number of other countries have entered this demographic transition to lower fertility, as socioeconomic development continues. Analyses of this demographic transition vary widely, but most analyze individual populations in isolation from others, and most come from fields outside the biological sciences. Here, we develop a population biological model of population dynamics in higher-income countries. Individual countries evolve through density-regulated growth, where gradual evolution toward higher population densities boosts productivity (and hence socioeconomic growth) through economics of agglomeration and scale, in turn reducing birth rates. The exchange of technology and capital between countries can further boost productivity gains in any given country, thus contributing to its demographic transition. As a result, countries can downregulate one another's population growth through mutual improvements in productivity. The model is fitted to time series data on population size, GDP per capita, and birth rates for the United States, the United Kingdom, and France. The metapopulation dynamics are also characterized across a range of parameter values close to the fitted values. This work may help advance population biological approaches to understanding the implications of the fertility demographic transition for modern human populations. This is relevant to developing long-term predictions of the earth's total population size, which must be based upon a model that incorporates underlying mechanisms.

Keywords: metapopulation; technology diffusion; human ecology; density dependence; urbanization 
In many population biological models, density dependence maintain population size below a specified carrying capacity that is a function of the environment and the characteristics of the species (Hassell, 1975; Berryman and Turchin, 2001). The concept of a carrying capacity has also been applied to humans, and attempts have been made to estimate the carrying capacity for the earth's human population (Cohen, 1995; Berryman, 1999; Berryman and Kindlmann, 2008). All these estimates of maximal human population size have been subsequently exceeded, as human population growth surged in the $20^{\text {th }}$ century (Cohen, 1995). The Earth's human population is estimated to have reached 6.5 billion in 2005, a figure nearly twice as large as that estimated for 1965 (3.3 billion) (UN, 2007a).

At the same time, the number of births per capita is shrinking in most countries as part of a major demographic transition in fertility that began in the middle of the industrial era (Galor, 2005). In Western Europe, this transition has caused the total fertility rate to drop below the replacement threshold, such that populations are projected to begin declining over the next 50 years (UN, 2008). Because of the demographic transition, Japan's population has been in decline since 2005 and is projected to continue declining (UN, 2007a). These declines have raised concerns about the impact of rising costs associated with aging populations (Faruqee and Muehleisen, 2003).

Many theoretical ecologists are taking increasing interest in human ecology and especially the problem of the demographic transition (Moses and Brown, 2003; Aarssen, 2005, 2007; Bettencourt et al., 2007a; Hamilton et al., 2009; Arbesman 2009). Their approaches often contrast sharply with socioeconomic approaches. For instance, Moses and Brown (2003) approach the demographic transition as a trade-off between the number 
of offspring and the energetic investment required to raise each individual offspring, which increases as socioeconomic systems develop. The authors develop an allometric principle that recovers the universally observed power law relationship between per capita fertility and per capita metabolic/extra-metabolic power consumption in countries, pre-industrial human, primate, and other mammalian populations (Moses and Brown, 2003). Another example of an ecologically-oriented approach is research by Bettencourt et al. (2007a) showing how a wide range of metropolitan indicators including gross domestic product (GDP), serious crimes, research and development (R\&D) employment etc. are strongly correlated to a city's population size via power laws. Causal relations underlying these power laws are explored and the correlations are used to generate a population biological model of urban population dynamics, with urban population size as the model variable (Bettencourt et al., 2007a).

Along similar lines, Bauch (2008) integrates data that relate GDP per capita, fertility, city size, and city size distributions to one another to create a simple population biological model of human population dynamics after the industrial era. The model suggests that the demographic transition may be a manifestation of density-dependent population growth (Bauch, 2008). The interpretation of density dependence stems from the observation that higher population density in a developed economy fosters economies of scale, agglomeration, and innovation (Bettencourt et al., 2007a), resulting in higher income per capita and thus causing a demographic transition to reduced fertility. The author fitted the model to long-term time series data on fertility, GDP per capita, and population size for the United States, France, and Japan individually. However, a good fit was only possible when an exogenous term representing the impact of technology and capital diffusion from 
other countries in the form of exponentially rising productivity per capita was added to the model (Bauch, 2008).

Both Bettencourt et al (2007a) and Bauch (2008) used data and observations from economics and demography, however the conceptual framework of their research is that of theoretical ecology, and their models are classical population biological models where the sole dynamic variable is population size.

Most hypothesized causes of the demographic transition point to some aspect of socioeconomic development and focus on causes and effects of the transition in individual populations (Becker et al., 1990; Bongaarts, 2003; Friedlander and Feldmann, 1993). Very few have considered these effects in the context of an interconnected world where populations depend upon one another's labour, technology and capital. However, these interconnections can be vitally important. The diffusion of research and development between countries and its impact on productivity has often been studied by economists. For instance, Coe and Helpman (1995) developed a model that treats technological progress as driven by commercially-orientated innovation efforts. They found that foreign R\&D has a beneficial effect on domestic productivity. They also found that rates of return on R\&D in terms of domestic output and international spillovers were very high in countries that were trade partners. Moreover, while foreign R\&D is significant for the productivity of larger economies, foreign R\&D capital may be as important as the domestic R\&D capital stock in the smaller economies in the Organization for Economic Co-operation and Development (OECD) countries. Models rooted in the concept that technological change drives economic growth have been extensively explored by others (Romer, 1990; Eaton and Kortum, 1999; Borensztein et al., 1998; Keller, 2000). Bilateral trade and foreign direct investment (FDI) 
as important channels for the diffusion of productivity increasing technological knowledge have been widely reported (Keller, 2002; Borensztein et al., 1998). Patent citations, new patents, patent applications and data on R\&D input (employment and investment) have often been used as a measure of knowledge diffusion (Keller, 2002). Interestingly, numbers of new patents, inventors, $R \& D$ establishments, $R \& D$ employment and private $R \& D$ employment, are also related to a city's population size by a power law (Bettencourt et al., 2007a).

These economic analyses suggest that socioeconomic systems are closely integrated not only through the exchange of labour (which corresponds to migration in metapopulations) but also technology and capital. Together with the (likely causal) inverse relationship between socioeconomic development and fertility observed in the current demographic transition, these analyses imply that countries that share R\&D and technology can down-regulate one another's population growth through mutual improvements in productivity and hence rising income per capita.

Here, we extend the single population density-dependent growth model proposed in Bauch (2008) to a metapopulation-like model where the inflow of technological knowledge from other populations can influence a country's productivity and hence population dynamics, through the mechanisms summarized in the preceding paragraphs. We adopt a population biological perspective, in the sense that population density is the sole state variable of the model. The interaction term representing how the inflow of technology and capital from other countries affects a given country's productivity is a function of the population density of the other countries in the system; however, the form of the interaction term is consistent with knowledge about the inter-relationship between population density, 
GDP per capita, productivity, and technology diffusion effects in developed countries. The model is fitted to economic and demographic data and its projections are studied. The resulting model is not closely grounded in biological principles, but it may serve as a step toward developing population biological models more explicitly grounded in biological principles by providing a common conceptual framework for thinking about both interacting human populations and interacting natural populations (metapopulations). In the following Methods section, we describe the model and how it was derived. In the Results section, we present the fitted model for a 3-country system consisting of the United States (US), the United Kingdom (UK), and France, and also characterize the model dynamics across a range of hypothetical populations. The paper concludes with a Discussion.

\section{Methods}

\section{Model derivation}

The model of Bauch (2008) was derived from empirical observations relating gross domestic product, city size, city size distributions, and birth rates. The model equation was

$$
\frac{d N}{d t}=N\left(\frac{k}{g^{s} N^{s(b-1)}}-d\right)
$$

where $N(t)$ is population density at time $t, d$ is death rate, $\sigma$ is the slope of the power law $b=b_{0} g^{-\sigma}$ relating a country's GDP per capita $g$ to its crude birth rate $b, \beta$ is the slope of the power law $g_{r}=\gamma n_{r}{ }^{\beta}$ relating urban GDP per capita $g_{r}$ to urban population size $n_{r}, \gamma$ is a productivity coefficient, $k=b_{0} \Omega^{b s} / \Delta^{s}$ is a constant, and $\Omega$ and $\Delta$ are parameters emerging from a quadratic relation between city size distribution and national population size in the 
same vein as Zipf's law. The parameters $\Omega=\sum_{r=1}^{\infty}\left(a_{0} r^{2}+b_{0} r+1\right)^{-1}$ and $\Delta=\sum_{r=1}^{\infty}\left(a_{0} r^{2}+b_{0} r+1\right)^{-b}$ where $r$ is the rank of the metropolitan city and $a_{0}$ and $b_{0}$ are constants. Equation (1) has the form of a classical model for density-regulated growth in a single population.

To account for the impact of labour, technology, and capital from other countries on a country's productivity and fertility in an exogenous way, the model was modified by: changing the productivity coefficient $\gamma$ in Equation (1) to $\gamma(t)=\gamma(0) e^{\rho t}$ (Bauch, 2008); assuming immigration occurred at some rate $\eta$; and fitting the death rate using a function of the form $d(N)=a+m e^{-c N}$ where $d(N)$ is the number of deaths per capita per year. The resulting extended model was

$$
\frac{d N}{d t}=N\left(\frac{k}{g(t) N^{s(b-1)}}-a-m e^{-c N}\right)+h
$$

where $k=b_{0} \Omega^{b s} / \Delta^{s}$. The fit of this extended model to long-term time series data on GDP per capita, crude birth rates, and population size for the United States, Japan, and France was reasonably good, whereas it was not possible to fit Equation (1) to these datasets.

Equation (2) is not fully satisfactory either conceptually or for longer-term predictions because it represents the influence of other countries exogenously through the term $\gamma(t)=\gamma(0) e^{\rho t}$, however the influence of other countries on a given country will not be a fixed constant because it must be assumed that other countries are evolving according to similar dynamics. In particular, the assumption of exponentially increasing $\gamma(t)$ may become unrealistic in the coming decades if more countries undergo a demographic 
transition and world population growth and productivity gains consequently slow (UN, 2007a).

Hence, in this work we extend Equation (2) into a dynamic multi-country model (akin to a metapopulation model) where the influence of other countries is represented endogenously. Each country is explicitly represented in the model, and the influence of other countries on a given country's productivity coefficient $\gamma$ is represented by an interaction term that is a function of the population size of other developed countries. This means we treat population size as (i) a direct measure of population size effects, such as productivity gains due to economies of scale, agglomeration, and innovation, but also (ii) as a proxy for any other economically important measures that are significantly correlated to population size and that enhance productivity, technology diffusion, and knowledge transfer. We base this assumption on the research described in the Introduction that relates population size to productivity-increasing factors such as capital inflow, R\&D investment, R\&D employment, patents, and technology diffusion. The modified productivity coefficient $\gamma$ for the metapopulation model is given by

$$
g_{i}(t)=g_{0 i} \exp \left(\sum_{j=1}^{n} s_{i} N_{j}+r_{i} t\right)
$$

where $\gamma_{i}(t)$ is the productivity coefficient for country $i, N_{j}$ is the population of country $j, \gamma_{0 i}$, $\rho_{i}$ and $s_{i}$ are constants and $i=1, \ldots, n$. The summation for country $i$ is from $j=1$ to $n$. The exponential term $\exp \left(\rho_{i} t\right)$ exogenously represents the impact of countries not included in the metapopulation. According to Equation (3), higher population densities in other countries boost a given country's productivity through the previously described effects. This functional form was chosen after considering several candidates and testing how well 
the resulting population models fit the empirical data. Models that employed other functional forms but gave inferior results are briefly introduced and discussed in the Results section.

As a result of Equation (3), the GDP per capita for country $i$ (Bauch, 2008) can be expressed as

$$
g_{i}=\left\lfloor g_{0_{i}} \exp \left(\sum_{j=1}^{n} s_{i} N_{j}+r_{i} t\right) \frac{\Delta}{\Omega^{b}}\right\rfloor N_{i}^{b-1}
$$

As in Bauch (2008), we can relate GDP per capita to birth rates using

$$
b_{i}=b_{0_{i}} g_{i}^{-s_{i}}
$$

where $b_{i}$ is the number of births per person per year and $b_{0 i}$ and $\sigma_{i}$ are constants. Likewise, death rates in country $i$ are described as in Bauch (2008) according to

$$
d_{i}\left(N_{i}\right)=a_{i}+m_{i} e^{-c_{i} N_{i}}
$$

where $a_{i}, m_{i}$ and $c_{i}$ are constants. Combining Equations (4-6) into a simple birth death model and adding an exogenous term for the net migration rate $\eta_{i}$ into country $i$, we obtain

$$
\frac{d N_{i}}{d t}=N_{i}\left(g_{0 i}^{s_{i}} \exp \left(\sum_{j \neq i} s_{i} N_{j}+r_{i} t\right)^{-s_{i}} \cdot \frac{k}{N_{i}^{s_{i}(b-1)}}-a_{i}-m_{i} e^{-c_{i} N_{i}}\right)+h_{i}
$$

where $k_{i}=b_{0_{i}} \Omega^{b s_{i}} / \Delta^{s_{i}}$ and $j=1, \ldots, n$. Model parameters are summarized in Table 1 .

\section{Data and methods for model fitting}

We used data from the US, UK and France to fit a three-country version of the model $(i=$ $1,2,3)$. These countries were chosen based on the availability of good economic and demographic data from the middle of the twentieth century onwards and their close economic connections during this time. The three-country model was fitted to time series 
data on population size using Eq. (7), GDP per capita (international dollars in 2000 constant prices) using Eq. (4), and birth rates using Eq. (5), simultaneously for the US, UK and France. As a result, 15 parameters were fitted to 9 timeseries simultaneously. Fits were performed both with and without the exogenous productivity term $\exp \left(\rho_{i} t\right)$ representing the influence of other countries not included in the metapopulation. The best-fit parameter values for $b_{0 i}, \gamma_{0 i}, \sigma_{i}, \rho_{i}$ and $s_{i}$ were estimated by minimizing least squares error between observed historical data and predicted values. Fitting was carried out using Berkeley Madonna Version 8.3. (We note that the values of $\Delta=16.80$ and $\Omega=25.73$ from the US as calculated by Bauch were used for the UK and France; because $\gamma_{0 i}$ is fitted from the data, and because $\gamma_{0 i}, \Delta$ and $\Omega$ appear in the same combination in Eqs. (4), (5) and (7), this has no effect on the goodness-of-fit.)

Historical yearly net migration rates were used to set the values of $\eta_{i}$ before 2005 (UN, 2008). The death rates were modelled using Eq. (6), which was fitted to historical data (UN, 2007b). Published data were used for historical GDP per capita (Heston et al., 2006), crude birth rates (UN, 2007b) and historical population sizes (Heston et al., 2006) for all three countries. Data for both birth and death rates were only available in 5 year intervals, so they were interpolated to generate yearly data.

\section{Results}

\section{Model fit to empirical data}

The fit of the model including the exogenous productivity term $\exp \left(\rho_{i} t\right)$ to the historical economic and demographic data was fairly good for all three countries (Figures 1-3, lefthand columns). The population size and GDP per capita of the US, UK and France were 
predicted to continue growing over the next 20 years, while the crude birth rate was predicted to continue its decline, at current net migration levels. The population sizes of France and UK, however, were predicted to level off more rapidly than the population size of the US. The projected relative decline in fertility in France was also steeper than in the US or the UK. The projected relative increase in GDP per capita was projected to be higher in the US and France than in the UK. The model was also run without the exogenous productivity term $\exp \left(\rho_{i} t\right)$ (Figures 1-3, right-hand columns) and the fit was similar to that with the exogenous productivity term.

Tables 2 and 3 provide the best fit values of $b_{0 i}, \gamma_{0 i}, \sigma_{i}, \rho_{i}$ and $s_{i}$ for the three countries for the model with and without the exogenous productivity term. While there is not much difference between the $R^{2}$ values of Table 2 and 3 (see captions of Figure 1-3), the best-fit values of most parameters vary somewhat depending on the presence or absence of the exogenous productivity term. We note that the relative sizes of the best-fit $s_{i}$ parameters for the US, the UK and France in both the model with and without the exogenous productivity term approximately follows the relative population sizes of the US, the UK, and France.

Several alternatives to the productivity function $\gamma_{i}$ in Equation (3) were also explored, such as replacing the country-specific parameter $s_{i}$ by a single parameter $s$ for all countries,

$$
g_{i}(t)=g_{i} \exp \left(\sum_{j=1}^{n} s N_{j}+r_{i} t\right)
$$

and another version where $s_{i}$ was replaced by $s N_{i}$,

$$
g_{i}(t)=g_{i i} \exp \left(\sum_{j=1}^{n} s N_{i} N_{j}+r_{i} t\right)
$$


where $i \neq j$. However, these two variants gave significantly worse fits to the data than Equation (3) (results not shown). A third variant that was explored was given by

$$
g_{i}(t)=g_{i i} \exp \left(\sum_{j=1}^{n} s_{i j} N_{j}+r_{i} t\right)
$$

where $i \neq j$ and $s_{i j}$ is a parameter that is specific to pairs of countries. This variant yielded slightly worse fits. Also, the best-fit values of $s_{i j}$ were inconsistent and difficult to interpret, suggesting there were too many degrees of freedom relative to available data under this approach (results not shown). (We note that under this approach, the number of parameters scales as $n^{2}$ with the number of countries $n$.)

\section{Characterization of model dynamics}

In order to characterize the long-term dynamics of the model, we generated projections for a hypothetical metapopulation of two countries, with parameter values close to the best-fit values in Tables 2 and 3. The model was again simulated in Berkeley-Madonna 8.3. No migration was assumed, and projections both with and without the exogenous productivity term were studied.

Figure 4 illustrates population dynamics for the case when the initial population size in the two countries is the same and all other parameters are identical, except $s_{1} \neq s_{2}$. In Figure 4a, we have the case $s_{1}>s_{2}$ and the model includes an exogenous productivity term. The population size of country 1 peaks at $t \approx 60$ years whereas country 2 grows steadily (note the difference in vertical scale in Figure 4a). This occurs because $s_{1}>s_{2}$ implies that country 2 is absorbing less technology from country 1 than vice versa. Therefore, GDP per capita growth is lower in country 2 but fertility and population growth are higher. Figure 
$4 \mathrm{~b}$ is the same as Figure 4a except that the exogenous productivity term is excluded. The population size of country 1 peaks earlier, at $t \approx 40$ years but at a higher level as compared to Figure $4 \mathrm{a}$ and then gradually declines, while country 2 grows rapidly during this period and always has a higher population size than country 1. In Figure 4c, the initial population size is the same in both countries and the exogenous productivity term is included, except now $s_{1}<s_{2}$ and both $s_{1}$ and $s_{2}$ are larger than in Figure 4a,b. As a result of having larger $s_{1}$ and $s_{2}$, both countries experience a gradual decline in population size, though country 2 declines more quickly because it is absorbing more technology and capital. In Figure 4d, the same case is studied except the exogenous productivity term is excluded. Now, the population size of country 1 grows very slowly, while the population size of country 2 declines.

In Figure 5a-d, the same cases are studied except that initial population sizes are allowed to be somewhat different. The results are qualitatively similar to Figure 4.

Figure 6 shows a parameter plane for the hypothetical two-country metapopulation without immigration and excluding the exogenous productivity term $\exp \left(\rho_{i} t\right)$. The countries are identical except for $s_{1}$ and $s_{2}$, the values of which are plotted on the axes of Figure 6. The parameter plane can be split into four regions of distinct model dynamics. The diagonal $s_{1}=s_{2}$ bisects the plane into two regions. Dynamics are symmetrical about this diagonal. Two other lines (one horizontal, one vertical) intersect at a threshold point $s^{*}$ on the diagonal $s_{1}=s_{2}$ and further demarcate the parameter plane into four regions. At $s^{*}$, the population size of both countries remains constant. In the first region, $\left\{\left(s_{1}, s_{2}\right) \mid\left(s_{1}>s_{2}\right)\right.$ $\left.\cap\left(s_{1}<s^{*}\right)\right\}$, both populations initially increase but $N_{l}$ (where productivity rises more rapidly due to higher uptake of technology from the other country) eventually decreases 
due to the more rapid increase in its GDP per capita. By comparison, $N_{2}$ increases monotonically and has lower GDP per capita than $N_{l}$. Dynamics in the second region, $\left\{\left(s_{l}\right.\right.$, $\left.\left.s_{2}\right) \mid\left(s_{1}<s_{2}\right) \cap\left(s_{2}<s^{*}\right)\right\}$ are symmetric to those in the first region, with dynamics for countries 1 and 2 being interchanged. The third region, $\left\{\left(s_{1}, s_{2}\right) \mid\left(\left(s_{1}>s_{2}\right) \cap\left(s_{1}>s^{*}\right)\right\}\right.$, is characterized by a continuously decreasing $N_{l}$, whereas $N_{2}$ initially decreases but later starts to increase. Dynamics in the fourth region, $\left\{\left(s_{1}, s_{2}\right) \mid\left(s_{1}<s_{2}\right) \cap\left(s_{2}>s^{*}\right)\right\}$, are symmetric to dynamics in the third region, with dynamics for countries 1 and 2 being interchanged.

The corresponding parameter plane for the case where the exogenous productivity term is included yields the same qualitative behaviour, except the threshold value $s^{*}$ moves closer to the origin (results not shown).

Finally, the model fitted to the empirical data for the US, UK and France and including the exogenous productivity parameter predicts an interesting result when plotted with and without net migration from 2010 onward. The extrapolation from 2010 onward (for all three countries) shows that reducing net migration from the projected positive value to zero reduces long-term population size and GDP per capita, while increasing the crude birth rate. This holds both in the short term and long term and is illustrated for the case of the US in Figure 7.

\section{Discussion}

This research analyzed a model of human populations in advanced countries that evolve internally through density-regulated growth (where urbanization drives socioeconomic development, thus reducing fertility), and where the influence of technology and capital 
from other countries in the "metapopulation" can strongly modulate an individual country's growth by boosting a country's GDP per capita and hence depressing its birth rate. Each country evolves according to similar dynamical principles, and population density is used as a proxy for economic indicators. The dynamics of the model were characterized, showing a broad range of possible dynamical behaviours depending on assumptions about how much productivity-boosting technology and capital can be absorbed from other countries (Figure 6). The model was also fitted to empirical data on GDP per capita, birth rate, and population size for a 3-country metapopulation consisting of the US, UK and France. The model fit was reasonably good, both with and without an exogenous productivity term representing the influence of countries not included in the metapopulation.

The $R^{2}$ values were only slightly higher in the model with the exogenous productivity term, compared to the model without the exogenous productivity term (Tables 2 and 3). This result implies that the temporal dynamics of the US, UK and France can primarily be explained in terms of technology diffusion among those three countries, and not of any other countries such as Japan or Germany. However, despite the historically close ties of these three countries, one might have expected to see a significantly improved model fit when the exogenous productivity term was included. Such a result suggests that the model is not optimally parsimonious, and that the fitting algorithm attempts to account for the influence of countries outside the metapopulation by altering the best-fit values of parameters relating to within-metapopulation dynamics.

However, this also suggests possible ways forward to build a more parsimonious model. For instance, $s_{i}$ could be re-formulated as $s_{i} t_{i j}$, where $s_{i}$ remains a fitted parameter 
relating to the capacity of country $i$ to absorb knowledge and capital, whereas $t_{i j}$ is not fitted but rather comes directly from empirical data on bilateral trade between countries. Under this approach, it would also be possible to inform the estimates of $s_{i}$ according to a country's stage of socioeconomic development using some commonly-used index.

Alternatively, in the extreme case of expanding the model to include all countries of the world, an exogenous productivity term could be dropped altogether. However, this would require data of sufficient quality for all countries. Additionally, equation (1) has been fitted only to data from countries whose current population was born primarily after the start of the demographic transition in fertility (Bauch, 2008). However, many countries have undergone recent demographic transitions and are developing rapidly expanding economies, meaning that their population structure is different from the world's most advanced countries. The model would have to be further modified to describe these countries undergoing rapid or recent demographic transitions, such as South Korea and China.

The issue of lower-income countries is also relevant to the issue of immigration, which was not endogenated in this model. Endogenating immigration would have required a separate submodel relating immigration to variables such as GDP per capita, and would have also introduced another set of variables that would have to be fitted. Hence, immigration was not endogenated in order to improve model parsimony, although this could be part of future work. Immigration would have to be endogenated in order for the model to be a true metapopulation model.

This approach may help point the way to developing more mechanistic models by showing that relatively simple models using only population size as a state variable can fit 
observed data and capture a range of possible dynamic behaviours. Future work should explore how to expand the mechanistic basis of these models. This work is only a small step toward purely population biological approaches to describing modern human population dynamics. A purely population biological model would have to depend more heavily on fundamental biological principles, such as bioenergetic constraints (Moses and Brown, 2003).

Models utilizing a similar underlying foundation may become more relevant in the coming decades as more countries enter a demographic transition to lower fertility and begin to concentrate their populations in rapidly developing urban centres. This worldwide transition is also relevant to sustainability issues. The peak and timing of the earth's maximal human population size must be projected as accurately as possible, and based upon good understanding of the underlying mechanisms, in order to project the maximal burden human populations will place upon the world's ecosystems. Under these circumstances, any reasonable model for the future population growth of a given country will need to explicitly acknowledge how countries are tightly coupled through a web of shared labour, technology and capital. The current model presents opportunities for further research on developing a fully mechanistic model of human "metapopulation" dynamics.

\section{Acknowledgements}

This research was supported by a Discovery Grant from the Natural Sciences and Research Council of Canada (NSERC) to Chris Bauch. 


\section{References}

Aarssen, L., 2005. Why is fertility lower in wealthier countries? The role of relaxed fertility selection. Population and development review 31(1), 113-126, doi: 10.1111/j.17284457.2005.00054.x.

Aarssen, L., 2007. Some bold evolutionary predictions for the future of mating in humans. Oikos 116 (10), 1768-1778, doi:10.1111/j.0030-1299.2007.16170.x.

Anderson, R., May, R. Infectious diseases of humans. Oxford University Press, 1991.

Arbesman, S., Kleinberg, J., Strogatz, S., 2009. Superlinear scaling for innovation in cities. Physical Review E 79 (1), 016115, doi: 10.1103/PhysRevE.79.016115

Bauch, C.T., 2008. Wealth as a source of density dependence in human population growth. Oikos 117 (12), 1824-32, doi: 10.1111/j.1600-0706.2008.17063.x.

Becker, G., Murphy, K., Tamura, R., 1990. Human capital, fertility, and economic growth. Journal of political economy 98 (s5), s12-s37, doi: 10.1086/261723.

Berrymann, A.A., 1999. Principles of population dynamics and their application. Garland Science, pp. 176-188. 
Berryman, A.A., Turchin, P., 2001. Identifying the density-dependent structure underlying ecological time series. Oikos 92, 265-270.

Berryman, A.A., Kindlmann, P., 2008. Population systems: a general introduction. $2^{\text {nd }}$ edition, Springer Verlag, pp. 199-203.

Bettencourt, L.M.A., Lobo, J., Helbing, D., 2007a. Growth, innovation, scaling, and the pace of life in cities. Proceedings of the National Academy of Sciences of the USA 104(17), 7301-7306, doi: 10.1073/pnas.0610172104.

Bettencourt, Luis M.A., Lobo, J., Strumsky, D, 2007b. Invention in the city: Increasing returns to patenting as a scaling function of metropolitan size. Research Policy 36 (1), 107 120, doi: 10.1016/j.respol.2006.09.026.

Bongaarts, J., 2003. Completing the fertility transition in the developing world: the role of educational differences and fertility preferences. Population studies 57 (3), 321-336, doi: $10.1080 / 0032472032000137835$.

Borensztein, E, Gregorio, J. D., Lee, J-W., 1998. How does foreign direct investment affect economic growth? Journal of International Economics, 45(1), 115-135, doi: 10.1016/S0022-1996(97)00033-0. 
Coe, David T., Helpman, E., 1995. International R\&D Spillovers. European Economic Review 39 (5), 859 - 887.

Cohen, J., 1995. How many people can the earth support? W.W. Norton \& Company, New York, doi: 10.1177/097172189600100216.

Eaton, J., Kortum, S., 1999. International Technology: Theory and Measurement. International Economic Review 40 (3), 537-570, doi: 10.1111/1468-2354.00028.

Faruqee, H., Muehleisen, M., 2003. Population aging in Japan: demographic shock and fiscal sustainability. Japan and the World Economy 15 (2), 185-210, doi: 10.1016/S09221425(02)00017-8.

Friedlander, D., Feldmann, C., 1993. The modern shift to below-replacement fertility: has Israel's population joined the process? Population studies 47 (2), 295-306, doi: 10.1080/0032472031000147026.

Galor, O., (2005). From stagnation to growth: Unified growth theory. Handbook of Economic Growth 1 (1), 171-293, doi:10.1016/S1574-0684(05)01004-X.

Hamilton M., Burger O., DeLong J., Walker R., Moses M., Brown J. Population stability, cooperation, and the invisibility of the human species. Proceedings of the National Academy of Sciences 106 (30), 12255-12260. 
Hassell, M., 1975. Density-dependence in single-species populations. The Journal of Animal Ecology 44 (1), 283-295, doi: 10.2307/3863.

Heston, A., Summers, R., and Aten, B., 2006. Penn World Table Version 6.2, Center for International Comparisons of Production, Income and Prices at the University of Pennsylvania, September 2006.

Keller, W., 2000. Do Trade Patterns and Technology Flows Affect Productivity Growth? World Bank Economic Review, Oxford University Press 14 (1), 17-47.

Keller, W., 2002. Geographic Localization Of International Technology Diffusion. American Economic Review 92 (1), 120-142, doi: 10.1257/000282802760015630.

Moses, M., Brown, J., 2003. Allometry of human fertility and energy use. Ecology Letters 6 (4), 295-300, doi: 10.1046/j.1461-0248.2003.00446.x.

UN, 2007a. The United Nations World Population Prospects URL: http://data.un.org/ (accessed June 20, 2009)

UN, 2007b. Population Division of the Department of Economic and Social Affairs of the United Nations Secretariat, World Population Prospects: The 2006 Revision and World 
Urbanization Prospects: The 2007 Revision, URL: http://esa.un.org/unup (accessed December 28, 2008).

UN, 2008. Population Division of the Department of Economic and Social Affairs of the United Nations Secretariat, World Population Prospects: The 2008 Revision, URL: http://esa.un.org/unpp, (accessed April 19, 2009).

US Census, 2007. United States Census Bureau (2007), The 2007 Statistical Abstract of the United States, Historical Statistics [WWW Document] URL: http://www.census.gov/compendia/statab/histstats.html (accessed 20 December 2007).

World Urbanization Prospects, 2004. World Urbanization Prospects: The 2003 Revision By United Nations Dept. of Economic and Social Affairs. Population Division, United Nations Published by United Nations Publications, 2004 
Table 1 - Parameters

\begin{tabular}{|c|c|c|}
\hline Parameter & Definition & Data Source \\
\hline$s_{i}$ & $\begin{array}{l}\text { Exponential coefficient governing impact of country } j \text { on } \\
\text { country } i \text {, from size-productivity relationship, equation (3) }\end{array}$ & Fitted \\
\hline$\rho_{i}$ & $\begin{array}{l}\text { Exponential coefficient determining influence of countries } \\
\text { outside the metapopulation on country } i \text {, from size- } \\
\text { productivity relationship, equation ( } 3 \text { ) }\end{array}$ & Fitted \\
\hline$\gamma_{0 i}$ & $\begin{array}{l}\text { Proportionality constant for country } i \text { from size-productivity } \\
\text { relationship, equation (3) }\end{array}$ & Fitted \\
\hline$\sigma_{i}$ & $\begin{array}{l}\text { Exponential coefficient from the GDP-birth rate relationship } \\
b_{i}=b_{0_{i}} g_{i}^{-\sigma_{i}} \text { where } g_{i} \text { is the GDP per capita of country } i \text {. }\end{array}$ & Fitted \\
\hline$b_{0 i}$ & $\begin{array}{l}\text { Proportionality constant from the GDP-birth rate relationship } \\
b_{i}=b_{0_{i}} g_{i}^{-\sigma_{i}}\end{array}$ & Fitted \\
\hline$\beta=1.2$ & $\begin{array}{l}\text { Exponential coefficient of productivity-size relationship } \\
g_{r}=\gamma n_{r}{ }^{\beta} \text { where } g_{r} \text { is metropolitan GDP of the } r^{\text {th }} \text { largest } \\
\text { city and } n_{r} \text { is its population size }\end{array}$ & $\begin{array}{l}\text { Bauch, 2008, } \\
\text { Bettencourt, } \\
2007 \mathrm{a}\end{array}$ \\
\hline$\Omega=25.73$ & $\begin{array}{l}\text { First composite parameter governing size-frequency } \\
\text { relationship of a country's metropolitan areas, } \\
\Omega=\sum_{r=1}^{\infty}\left(a_{0} r^{2}+b_{0} r+1\right)^{-1} \text {, where } a_{0} \text { and } b_{0} \text { are constants and } \\
r \text { is the rank of the metropolitan area. }\end{array}$ & Bauch, 2008 \\
\hline$\Delta=16.80$ & $\begin{array}{l}\text { Second composite parameter governing size-frequency } \\
\text { relationship of a country's metropolitan areas, }\end{array}$ & Bauch, 2008 \\
\hline
\end{tabular}




$$
\Delta=\sum_{r=1}^{\infty}\left(a_{0} r^{2}+b_{0} r+1\right)^{-b}
$$


Table 2: Best-fit parameter values for the model including the exogenous productivity term.

\begin{tabular}{cccc}
\hline Parameter & United States & United Kingdom & France \\
\hline$b_{0 i}$ & 0.6881 & 0.5481 & 0.9997 \\
$\gamma_{0 i}$ & 20.08 & 208.0 & 187.8 \\
$\sigma_{i}$ & 0.3755 & 0.3750 & 0.4350 \\
$\rho_{i}$ & $1.195 \times 10^{-10}$ & $8.809 \times 10^{-7}$ & $1.532 \times 10^{-7}$ \\
$s_{i}$ & $\mathrm{UK}$, Fr effect on US & US, Fr effect on UK & UK, US effect on Fr \\
& $3.872 \times 10^{-8}$ & $6.466 \times 10^{-9}$ & $6.900 \times 10^{-9}$ \\
\hline
\end{tabular}


Table 3: Best-fit parameter values for the model excluding the exogenous productivity term.

\begin{tabular}{cccc}
\hline Parameter & United States & United Kingdom & France \\
\hline$b_{0 i}$ & 0.3800 & 0.3517 & 0.3087 \\
$\gamma_{0 i}$ & 14.57 & 175.9 & 181.6 \\
$\sigma_{i}$ & 0.3167 & 0.3306 & 0.3137 \\
& & & \\
$s_{i}$ & UK, Fr effect on US & US, Fr effect on UK & UK, US effect on Fr \\
& $4.175 \times 10^{-8}$ & $7.022 \times 10^{-9}$ & $7.035 \times 10^{-9}$ \\
\hline
\end{tabular}




\section{Figure Captions}

$\underline{\text { Figure 1: }}$ Population versus time in US, empirical data (black) versus predicted values (grey) for the model with (a) and without (b) the exogenous parameter; GDP per capita versus time in US, empirical data versus predicted values for the model with (c) and without $(d)$ the exogenous parameter; birth rate (number of births per 1000 persons per year) versus time in US, empirical data versus predicted values for the model with (e) and without (f) the exogenous productivity parameter. $R^{2}$ values are $0.9989,0.9985,0.9922$, $0.9919,0.6721$, and 0.6591 for (a)-(f) respectively. $p$ values are $<10^{-9}$ in all cases.

Figure 2: Population versus time in UK, empirical data (black) versus predicted values (grey) for the model with (a) and without (b) the exogenous parameter; GDP per capita versus time in UK, empirical data versus predicted values for the model with (c) and without (d) the exogenous parameter; birth rate (number of births per 1000 persons per year) versus time in UK, empirical data versus predicted values for the model with (e) and without (f) the exogenous parameter. $R^{2}$ values are $0.9707,0.9706,0.9918,0.9907,0.7203$, and 0.7122 for (a)-(f) respectively. $p$ values are $<10^{-11}$ in all cases. 
Figure 3: Population versus time in France, empirical data (black) versus predicted values (grey) for the model with (a) and without (b) the exogenous parameter; GDP per capita versus time in France, empirical data versus predicted values for the model with (c) and without (d) the exogenous parameter; birth rate (number of births per 1000 persons per year) versus time in France, empirical data versus predicted values for the model with (e) and without (f) the exogenous parameter. $R^{2}$ values are $0.9976,0.9956,0.9428,0.9382$, 0.8711 , and 0.8575 for (a)-(f) respectively. $p$ values are $<10^{-10}$ in all cases.

Figure 4: Time evolution of two hypothetical populations $N_{l}$ and $N_{2}$ for the same starting population size, with $(\mathrm{a}, \mathrm{c})$ and without $(\mathrm{b}, \mathrm{d})$ the exogenous productivity term. $N_{l}$ is the grey line and $N_{2}$ is the black line. Note the difference in vertical scales. $s_{1}=10^{-3}$ and $s_{2}=$ $10^{-4}$ for $(\mathrm{a}, \mathrm{b}), s_{1}=10^{-2}$ and $s_{2}=10^{-1}$ for $(\mathrm{c}, \mathrm{d})$ Other parameter values: $N_{1}(0)=N_{2}(0)=1000, \rho_{1}$ $=\rho_{2}=8 \times 10^{-2}, \frac{b_{0 i} \Omega^{b s_{i}}}{g_{0 i}^{s_{i}} \Delta^{s_{i}}}=0.1, \beta=1.2, \sigma_{l}=\sigma_{2}=0.318$, and $a_{i}=8.7 \times 10^{-4}, b_{i}=6.46 \times 10^{-4}, c_{i}=$ $2.58 \times 10^{-10}$ for $i=1,2$.

Figure 5: Time evolution of two population sizes for different starting population sizes, with $(\mathrm{a}, \mathrm{c})$ and without $(\mathrm{b}, \mathrm{d})$ the exogenous productivity term. $N_{l}$ is the grey line and $N_{2}$ is the black line. $s_{1}=10^{-3}$ and $s_{2}=10^{-4}$ for (a, b), $s_{1}=10^{-2}$ and $s_{2}=10^{-1}$ for (c, d). Other parameters are $N_{l}(0)=1500, N_{2}(0)=1000, \rho_{1}=8 \times 10^{-2}, \rho_{2}=8 \times 10^{-2}, \frac{b_{0 i} \Omega^{b s_{i}}}{g_{0 i}^{s_{i}} \Delta^{s_{i}}}=0.1, \beta=1.2$ $\sigma_{1}=\sigma_{2}=0.318$, and $a_{i}=8.7 \times 10^{-4}, b_{i}=6.46 \times 10^{-4}, c_{i}=2.58 \times 10^{-10}$ for $i=1,2$. 
Figure 6: Parameter plane for a hypothetical two-country model excluding the exogenous productivity parameter. Horizontal axis denotes value of $s_{1}$ and vertical axis denotes value of $s_{2}$.

Figure 7: Projected time series of population size (a), GDP per capita (b), and birth rate (c) for the US model including (grey lines) and excluding (black lines) net migration from 2010 onwards. 